\title{
SOME SOCIAL AND ENVIRONMENTAL VARIABLES EFFECTING RURAL PEOPLE BEHAVIOR REGARDING WATER STREAMS ( VILLAGE FIELD STUDY IN SHARKIA GOVERNORATE )
}

Mohamed, Zeinab A. and M. H.n Hasan

Agric. Extension and Rural Development .,Res. Inst.,Agric. Res. center

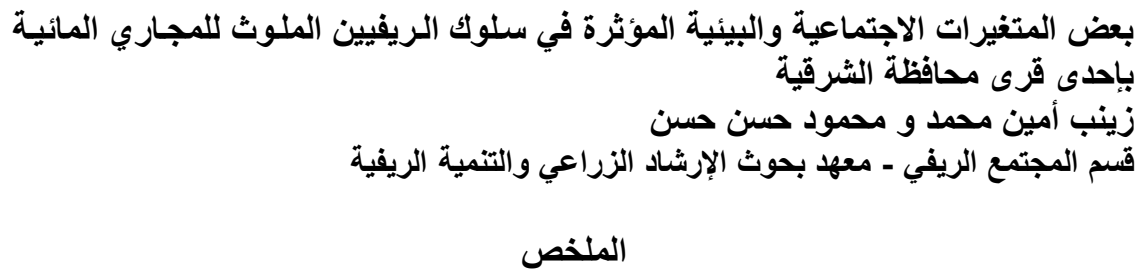

\section{المقدمة والمشكلة البحثية}

السلوك البيئي للريفيين يثبير إلى استجابة الريفيين أو ردود أفعالهم سواء كانت لفظية أو حركية ، ظاهريـة

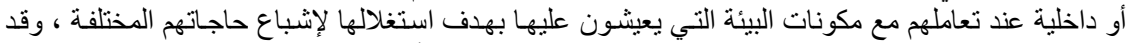

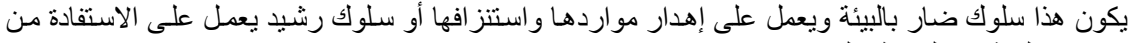

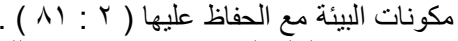

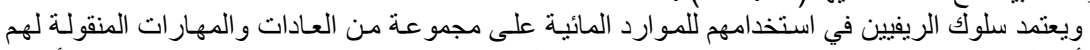

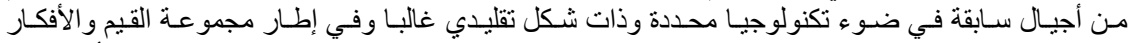

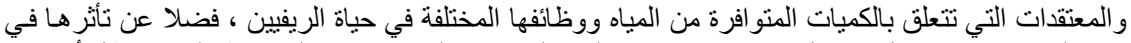

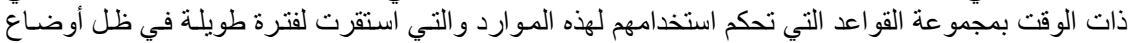




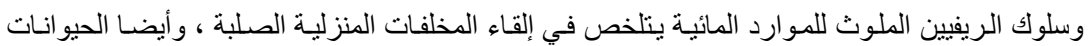

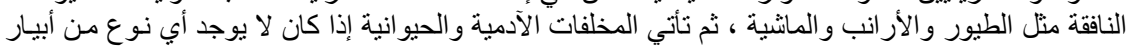

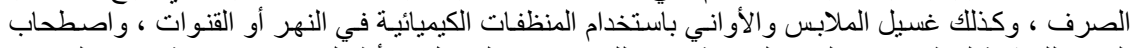

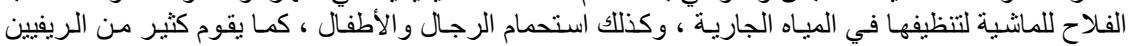

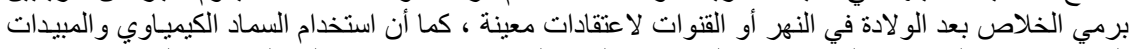

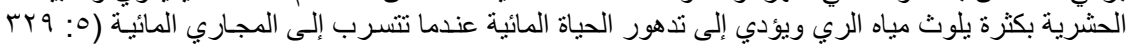

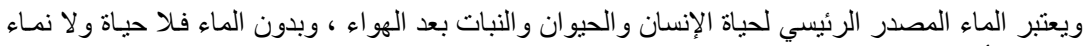

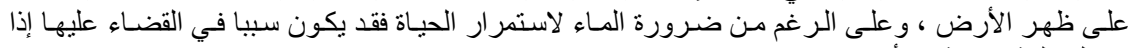

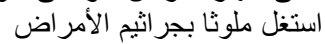

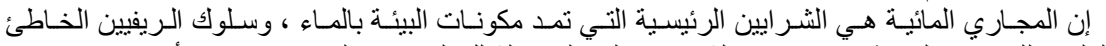

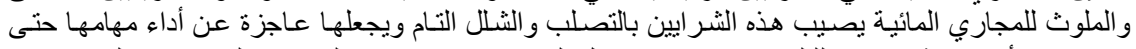

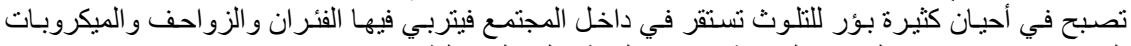

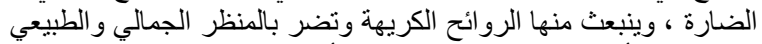

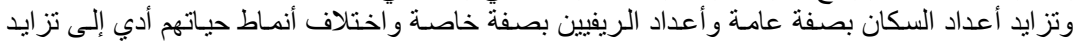

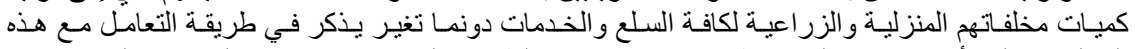

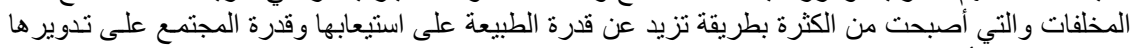

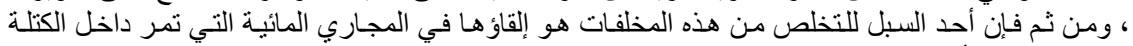

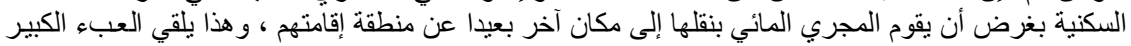

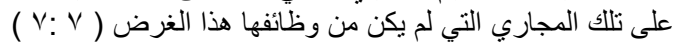

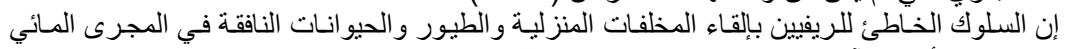

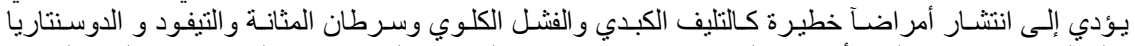

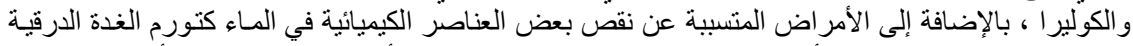

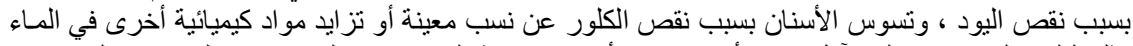

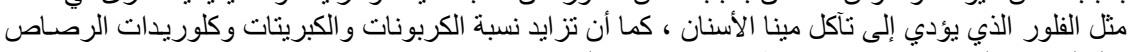

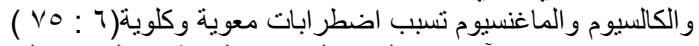

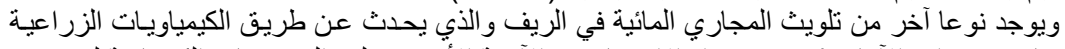

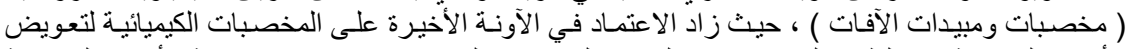

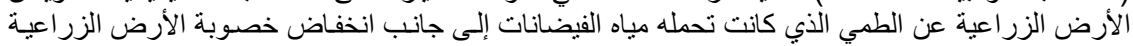

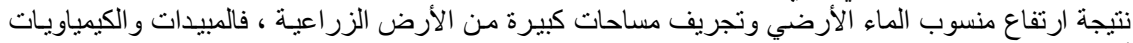

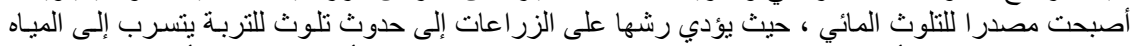

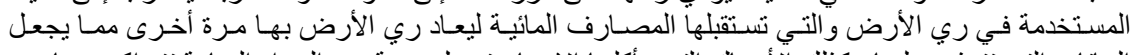

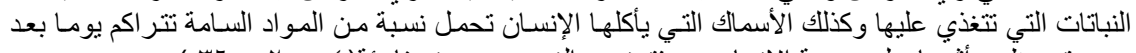

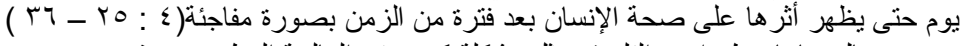

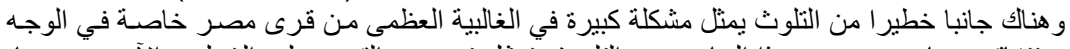

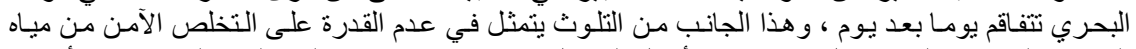

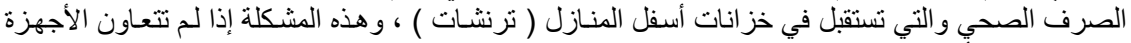

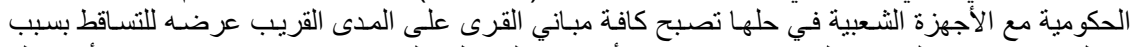

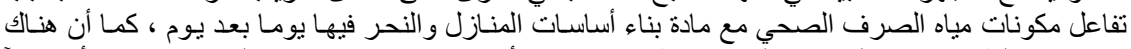

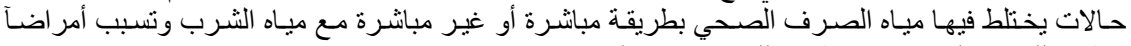

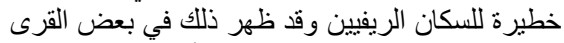

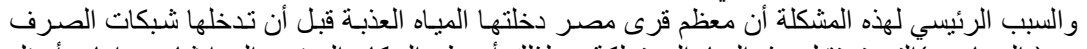

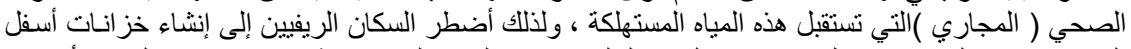

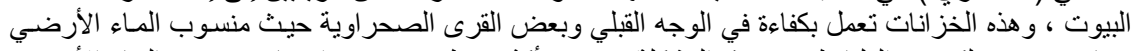

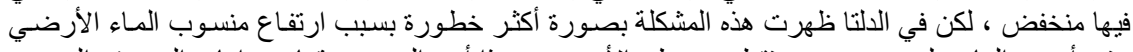

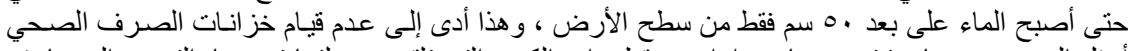

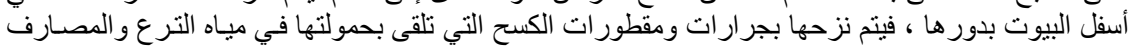




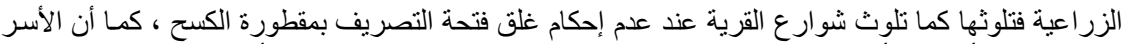

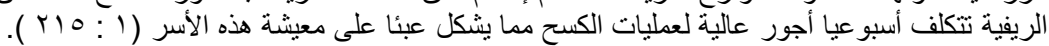

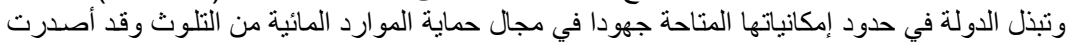

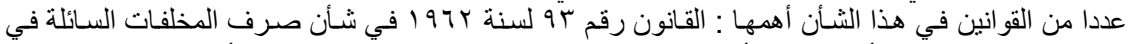

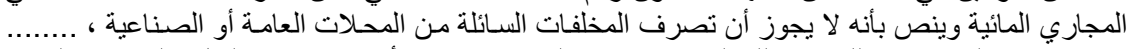

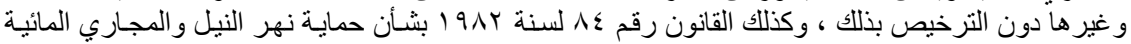

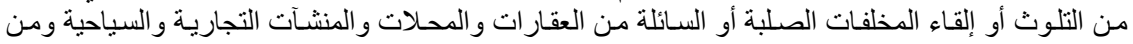

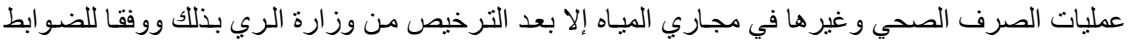

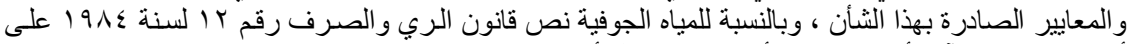

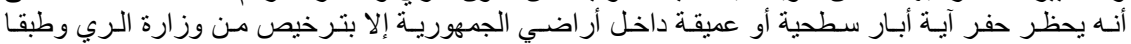

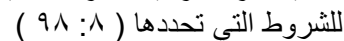

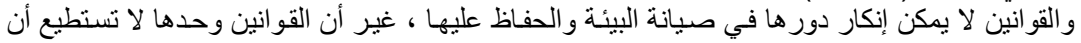

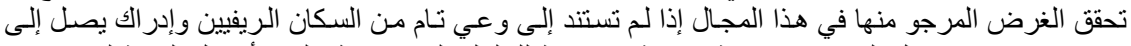

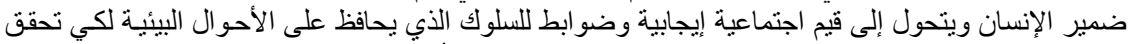

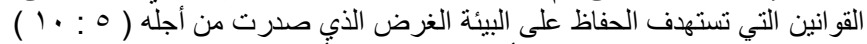

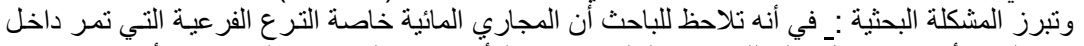

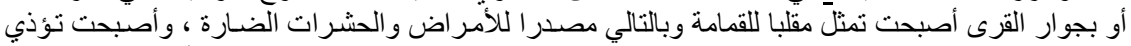

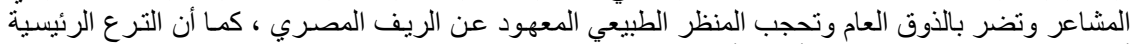

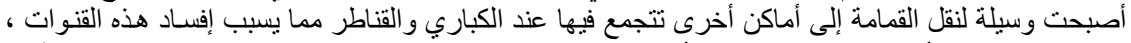

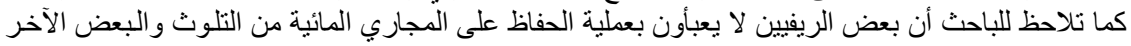

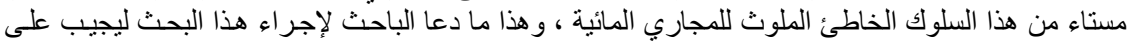

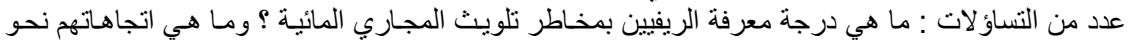

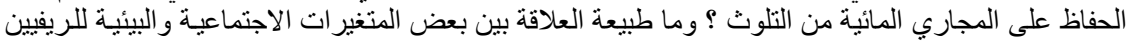

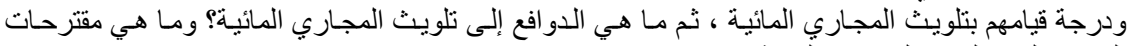
الريفيين لمنع تلويث المهاريث المباري المبائية ؟

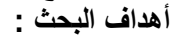

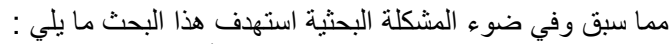

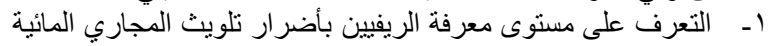

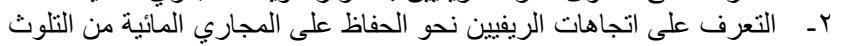

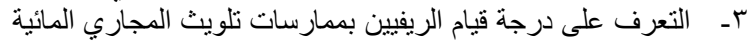

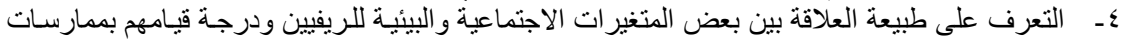
تلويث المجاري المائية

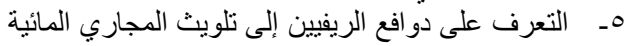

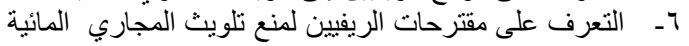

التعاريف الإجرائية : المجائة :

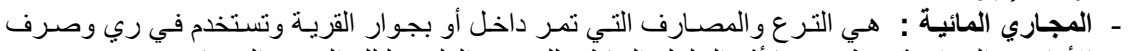

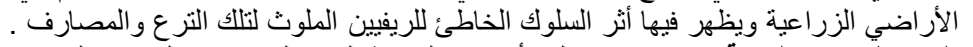

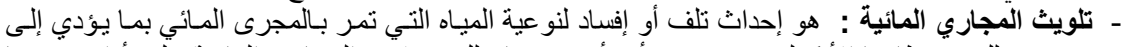

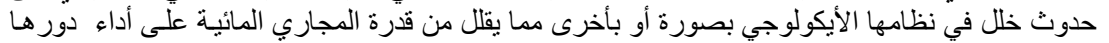

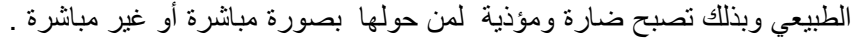

الفروض البحثية : لتحقيق هدف الدراسة الرابع تم صياغة الفرض البحثي التالي :

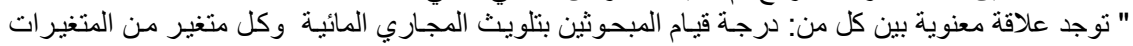

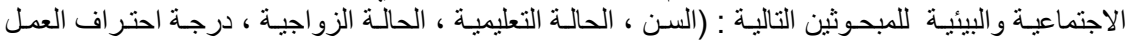

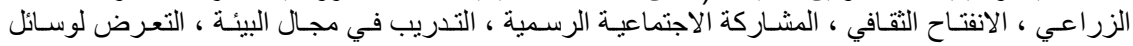

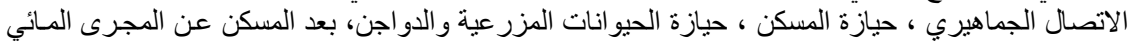


، توفر إمكانيـات الاستفادة أو التخلص مـن المخلفـات ، طريقة الحصـول على الميـاه النقيـة ، التأثز بالصـرف

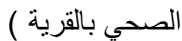
الطريقة البحثية : البرية

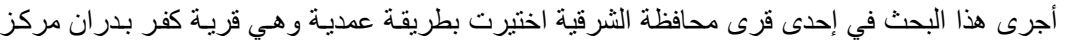

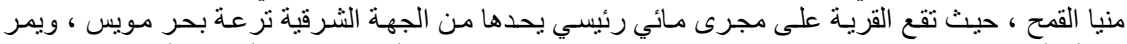

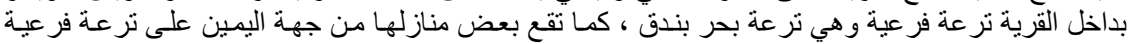

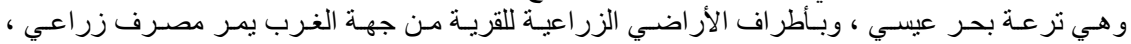

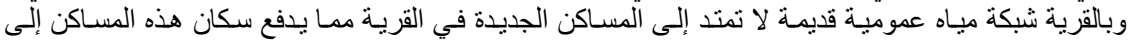

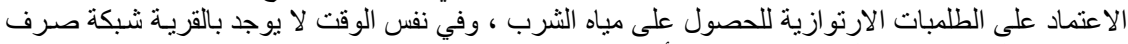

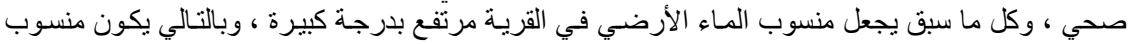

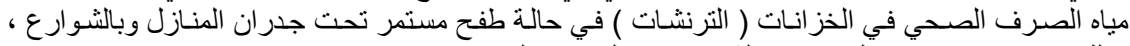

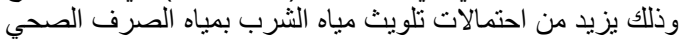

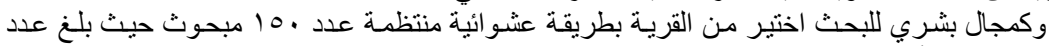

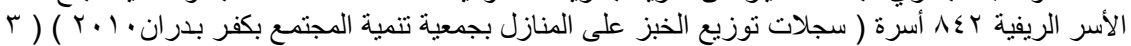

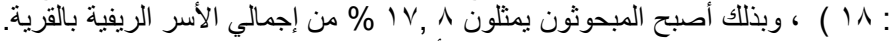

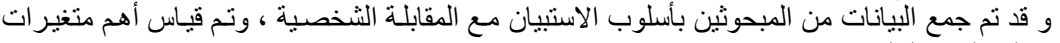

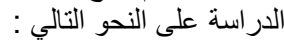

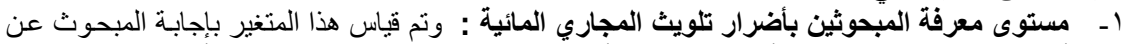

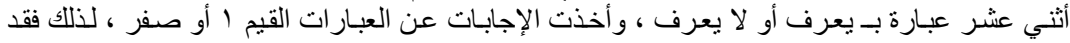

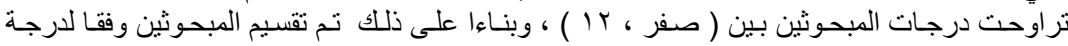

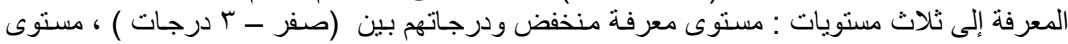

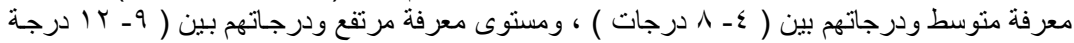

r- اتجاهات المبحوثون نحو الحفاظ على المجاري المائية من التلوث: وتم قياس هذا المتغير بإجابة

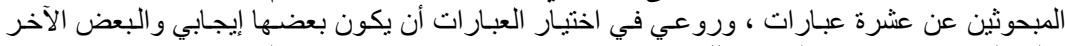

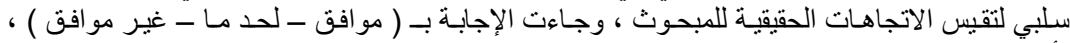

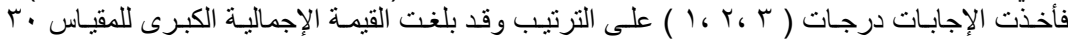

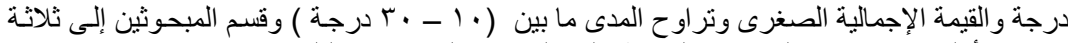

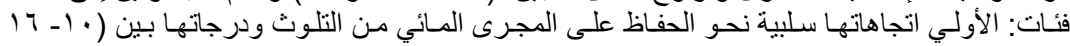

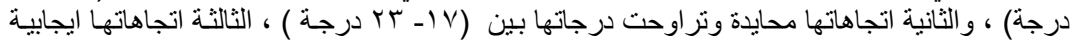

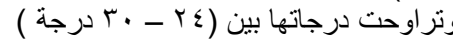

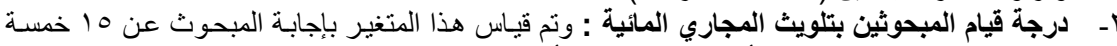

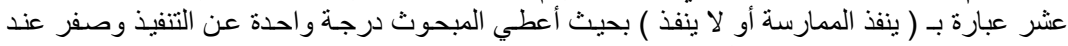

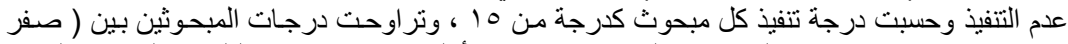

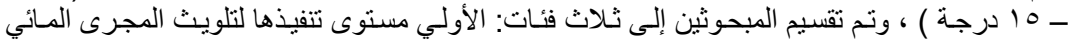

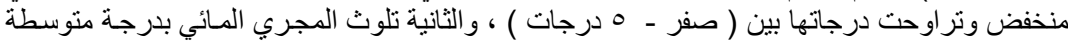

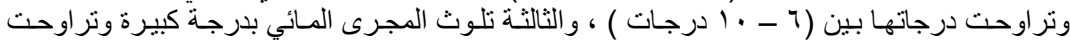

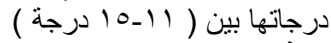

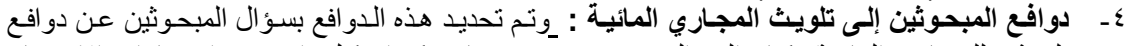

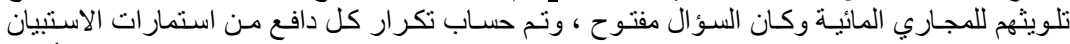

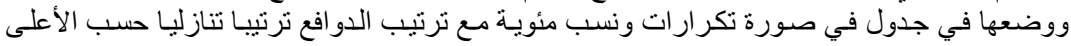

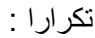

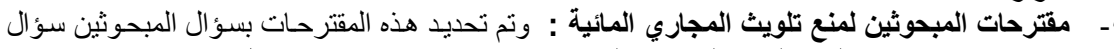

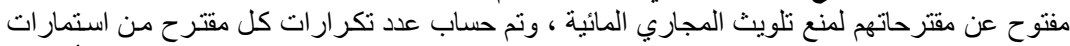

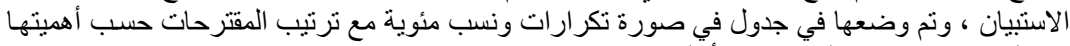

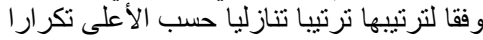

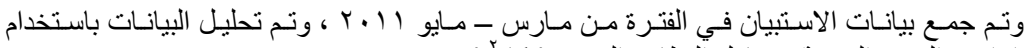

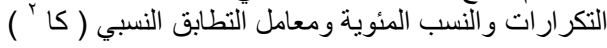


وصف المتغيرات الاجتماعية والبيئية للمبحوثين : أولا : المتغيرات الاجتماعية : الاجنماعة :

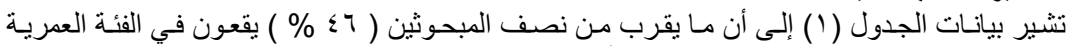

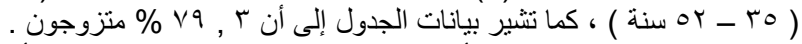

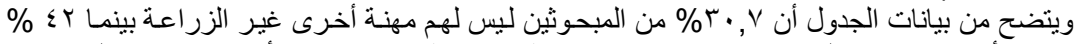

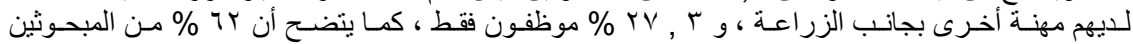

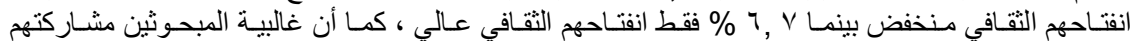
الاجتماعية الرسمية في عضوية المنظمات منخفضة ، ونسبة بسيطة تمثل ه r, V \% فقط مشاركتهم الاجتماعية

الرسمية عالية

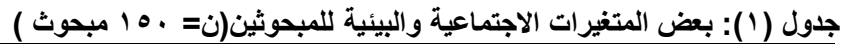

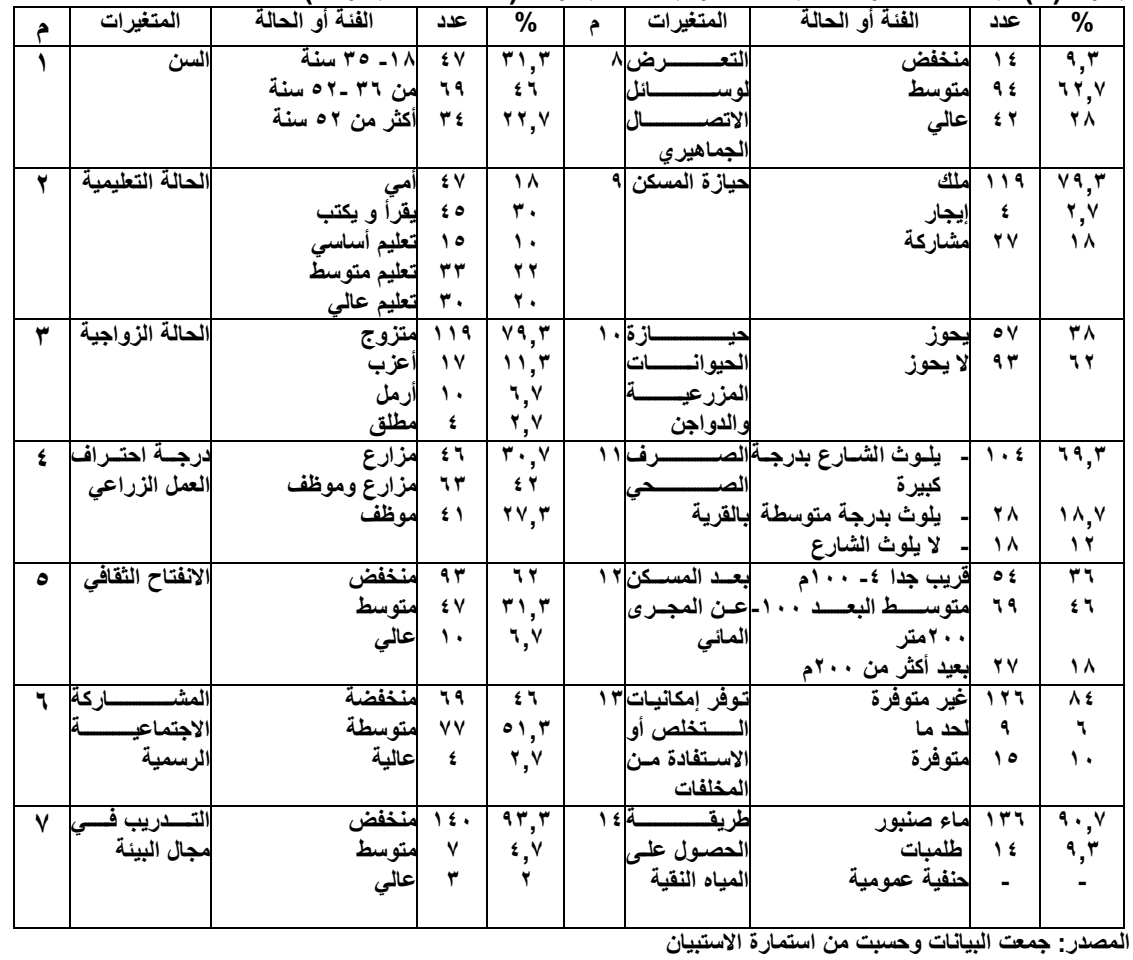

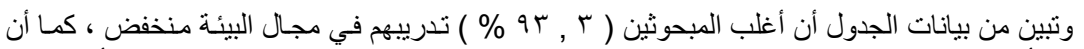

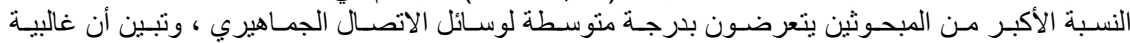

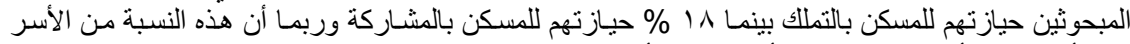

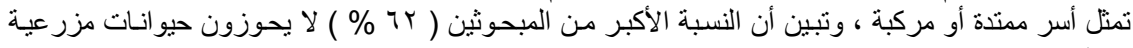

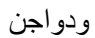
ثانيا : المتغيرات البيئية :

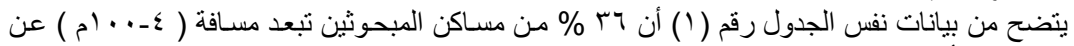

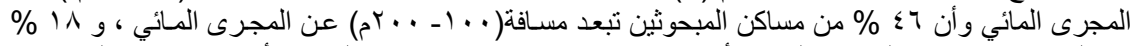

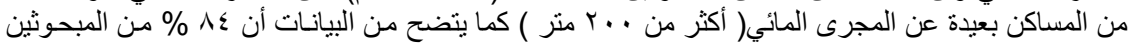

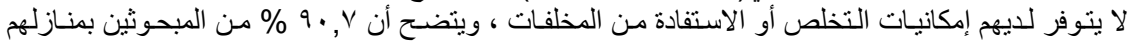




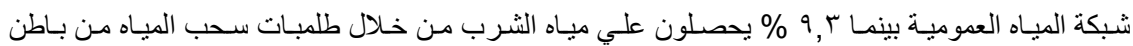

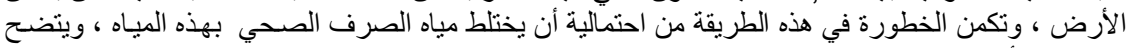

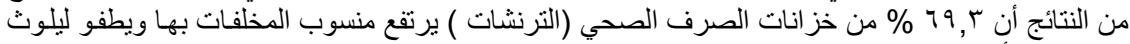

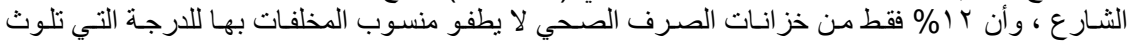

\section{النتائج ومناقشتها}

أولا : مستوى معرفة الريفيين بأضرار تلويث المجاري المائية :

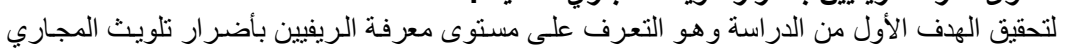

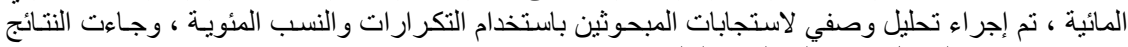

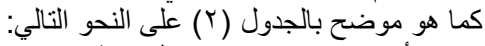

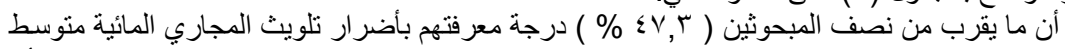

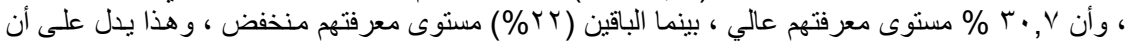

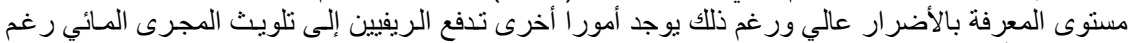
معرفتهم بالأضر ار بعرار

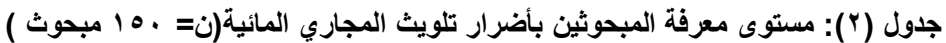

\begin{tabular}{|c|c|c|c|c|}
\hline مستوى المعرفة & العدد & $\%$ & لمتّوسط الحسابي & الانحراف المعياري \\
\hline معرفة منخفض (صفر - r ) & Tr & KY & \multirow{4}{*}{ r. . 9} & \multirow{4}{*}{7.01} \\
\hline معرفة متوسط (؟ - A ) & v) & $\varepsilon v, r$ & & \\
\hline معرفة عالي (9- Y Y ( ) & $\leqslant 7$ & $r \cdot, v$ & & \\
\hline الإجمالى & 10. & $1 \ldots$ & & \\
\hline
\end{tabular}

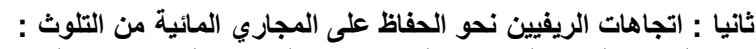

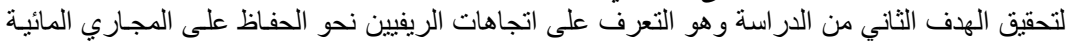

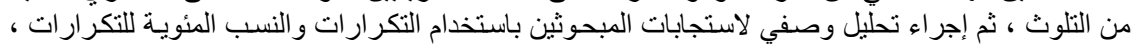

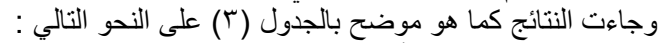

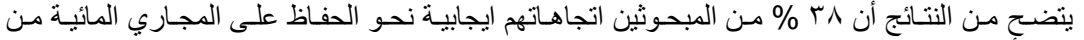

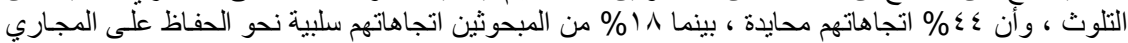

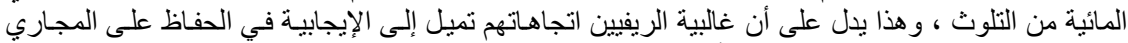

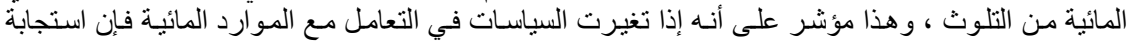
الريفيين ستكون سريعة إلى الأفضل

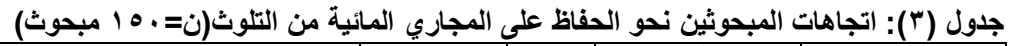

\begin{tabular}{|c|c|c|c|c|}
\hline الاتجاهات & العدد & $\%$ & المتوسط الحسابي & الانحر اف المعيازي \\
\hline اتتجاهات سلبية ( •1 - 17 ) & $T V$ & 11 & \multirow{4}{*}{ r.r } & \multirow{4}{*}{$r . \varepsilon}$. \\
\hline |أتجاهات محايدة (YY - (YY) & 77 & $\varepsilon \varepsilon$ & & \\
\hline 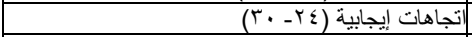 & ov & $r \Lambda$ & & \\
\hline |لإإجمالي | ل المالي & 10. & $1 \ldots$ & & \\
\hline
\end{tabular}

ثالثا : درجة قيام الريفيين بممارسات تلويث المجاري المائية :

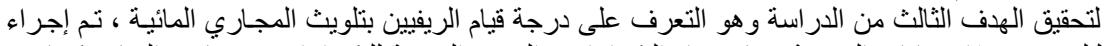

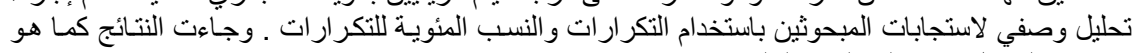
موضح بالجدول (乏) على النحو التالي : 


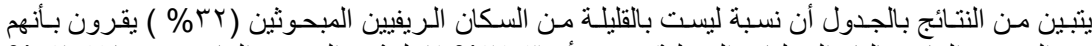

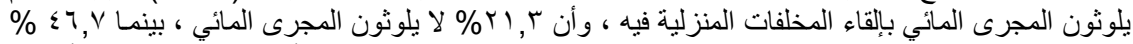

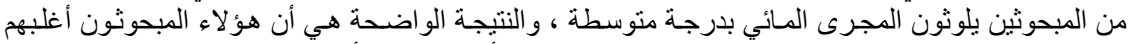

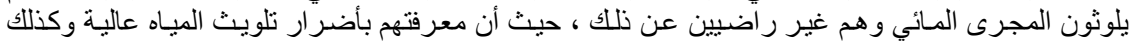

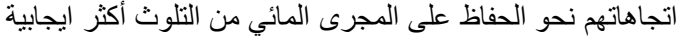

جدول ( ) ): درجة قيام الريفيين بممارسات تلويث المجاري المائية (ن = • 10 مبحوث )

\begin{tabular}{|c|c|c|c|c|}
\hline |الممارسات & العدد & $\%$ & |لمتوسط الحسابي & الاتحراف المعياري \\
\hline لبلوث المجاري (صفر - 0) & $\varepsilon \Lambda$ & rT & \multirow{4}{*}{$1 . \varepsilon 1$} & \multirow{4}{*}{ V.r. } \\
\hline لبلوث لحد ما (1 - - 1 ) & v. & $\varepsilon 7, \mathrm{~V}$ & & \\
\hline لا يلوث (1) & rY & $r, r$ & & \\
\hline | الإجمالي & 10. & $1 \ldots$ & & \\
\hline
\end{tabular}

رابعا : طبيعة العلاقة بين بعض المتغيرات الاجتماعيـة والبيئية للريفيين ودرجة قيـامهم بممارسـات تلويث المجاري المائية : المعائ

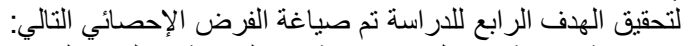

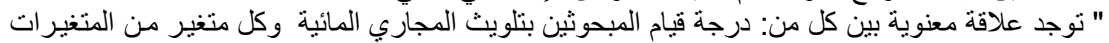

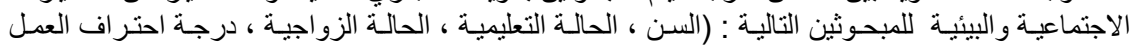

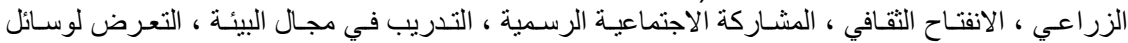

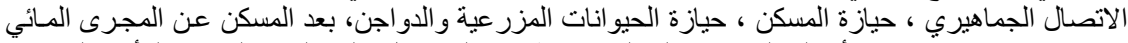

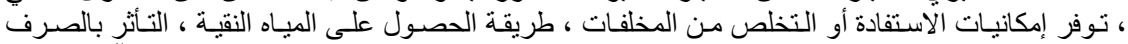

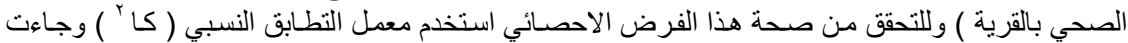

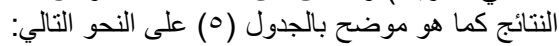

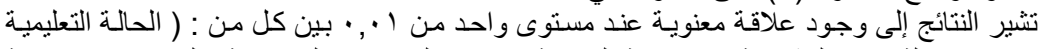

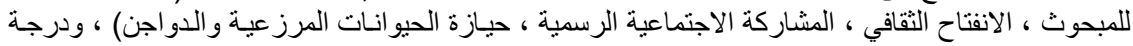

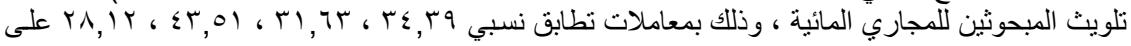

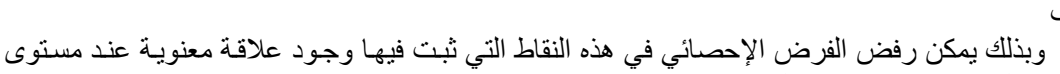
الترتيب

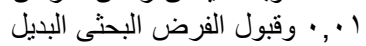

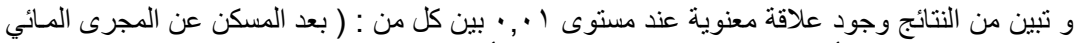

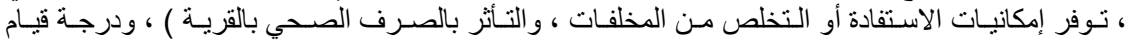

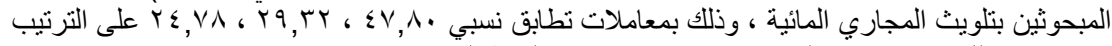

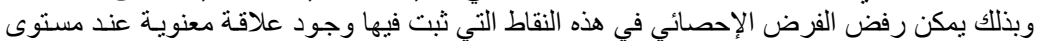

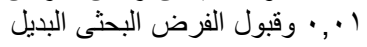

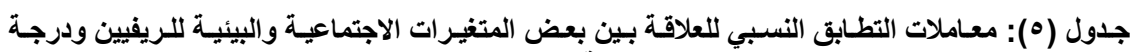
قيامهم بممارسات تلويث المجاتي المعاري المائية

\begin{tabular}{|c|c|c|c|c|}
\hline المتغيرات الاجتماعية & & قيم مربع كاي & المتغيرات البيئية & قيم مربع كاي \\
\hline السن & -1 & $99, r$. & 1- بعد المسكن عن المجري المائي & $x \times \leq v, \wedge$. \\
\hline الحالة التعليمبة & $-r$ & $x \times<\leqslant, 19$ & 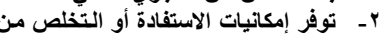 & $x$ \\
\hline الحالة الزواجيّة & - & $0, r^{r}$ & المخلفات & \\
\hline درجة احتراف العمل الزراعي & ـ & $\{, \leqslant \wedge$ & r- طريقة الحصول على المياه النقية & ४, १४ \\
\hline الانفتاح الثقافي م ال & - & ri, r & عـ الصرف الصحي بالقرية" " & $x \times r \leqslant, y \wedge$ \\
\hline المشاركة الاجتَّماعية الرسمية & -7 & $x \leqslant \varepsilon, 01$ & & \\
\hline التلدريب في مجال البيئة & $-v$ & $r, i$ & & \\
\hline التعرض لوستائل الاتصال الجماهيري & $-\Lambda$ & 1,91 & & \\
\hline حيازة المسكن & -9 & $ד, Y \mu$ & & \\
\hline حيازة الدواجن والحيوانات & -1. & $x \times r h, i r$ & & \\
\hline
\end{tabular}


المصدر : جمعت البيانات وحسبت من استمارات الاستبيان

خامسا : دوافع الريفيين إلى تلويث المجاري المائية :

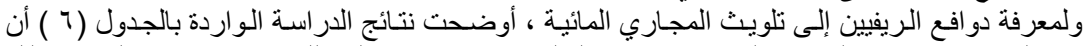

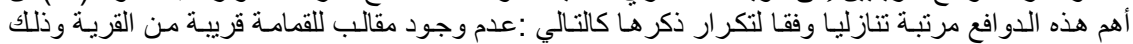

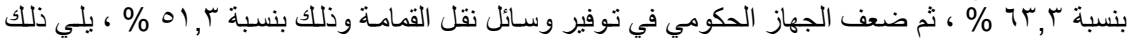

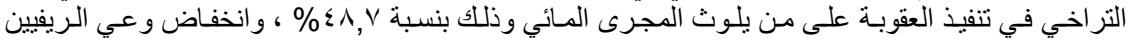

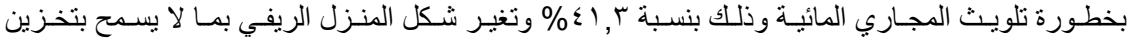

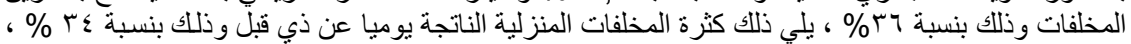

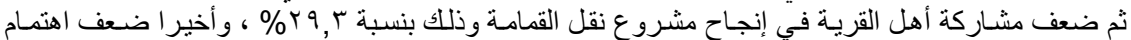

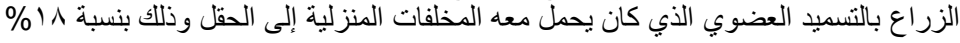

جدول (؟): دوافع الريفيين إلى تلويث المجاري المانية (ن = .0 10 مبحوث )

\begin{tabular}{|c|c|c|c|}
\hline & 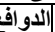 & 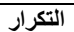 & $\%$ \\
\hline عدم وجود مقالب للقمامة قريبة من القرية & -1 & 90 & (r \\
\hline ضعف الجهاز الحكومي في توفير وسائل لنقل القمامة & $-r$ & VY & $01, r$ \\
\hline التر اخي في تتفيذ العقوبة على من بلوث المجرى المائي & $-r$ & VT & $\varepsilon \wedge, \gamma$ \\
\hline انخفاض وعي الريفيين بخطورة تلويث المجاري المائية & $-\varepsilon$ & Tr & $\sum 1, r$ \\
\hline تغير شكل المنززل الريفي بما لا بسمح بتخزين المخلفات & -0 & $0 \leqslant$ & $r, \cdots$ \\
\hline كثرة المخلفات المنزلية الناتجة يومياً & -7 & 01 & rะ \\
\hline ضعف مشاركة أهل القرية في إنجاح مشروع نقل القمامة & $-v$ & $\varepsilon \varepsilon$ & rq, r \\
\hline ضعف اهتمام الزراع بالتسميد العضوي الذي كان يحمل معه المخلفات إلى الحقل & $-\wedge$ & TV & 11 \\
\hline
\end{tabular}

سادسا : مقترحات الريفيين لمنع تلويث المجاري المائية :

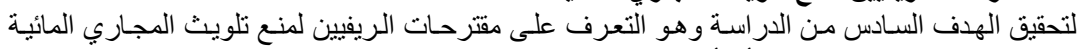

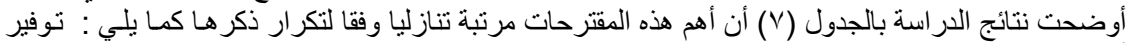

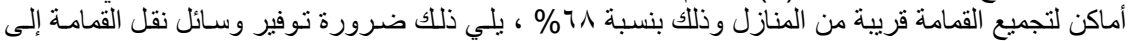

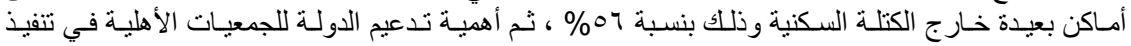

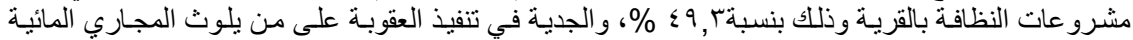

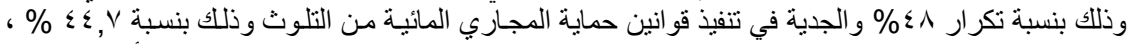

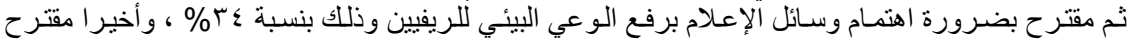

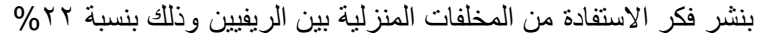

جدول (V): مقترحات المبحوثين لمنع تلويث المجاري المائية (ن= . 10 مبحوث )

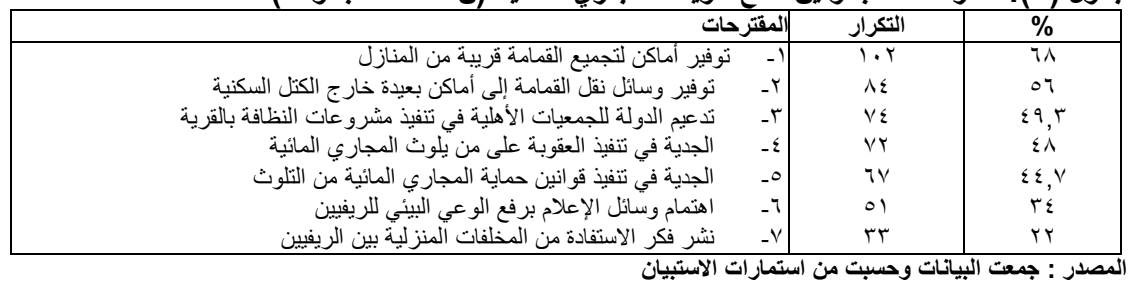

المصدر : جمعت البيانات وحسبت من استمارات الاستيبان الان

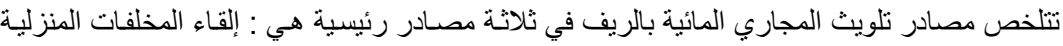

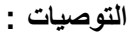

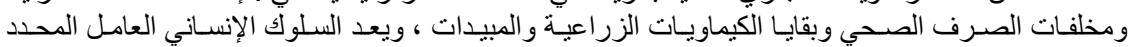

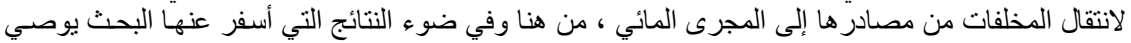
بالآتي : 


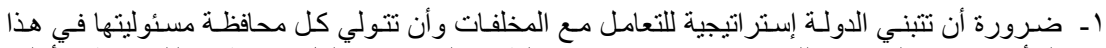

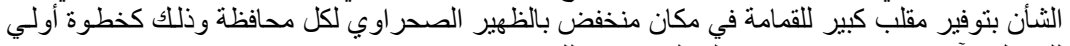

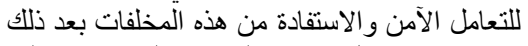

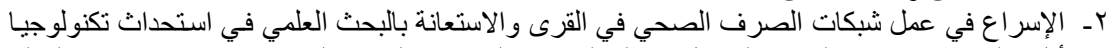

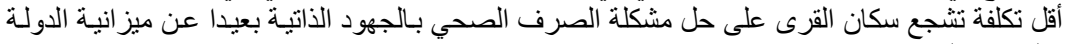

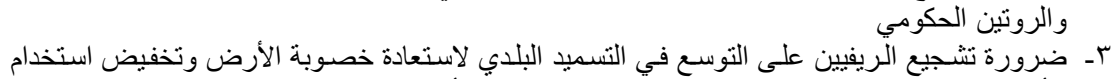

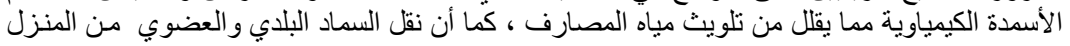

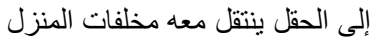

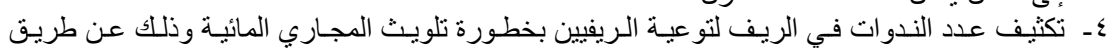

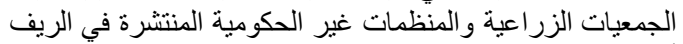

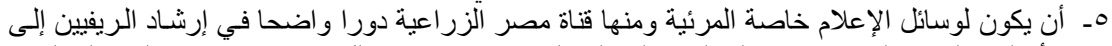

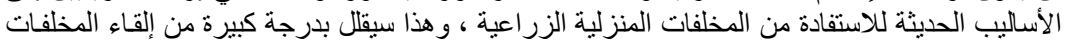
في المجاري المائية 7- ضرورة التشدد في تنفيذ القو انين المتعلقة بحماية المجاري المائية من التلوث خاصة التي تعاقب من يلقي بالمخلفات المنزلية ومخلفات الصرف تلفن الصحي في المجاري المائية .

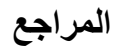

$$
\begin{aligned}
& 1 \text { أـأرناؤوط ، محمد السيد ، " الإنسان وتلوث البيئة "الهيئة المصرية العامة للكتاب ،القاهرة ، } 1999
\end{aligned}
$$

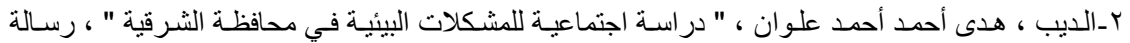

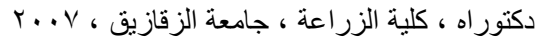

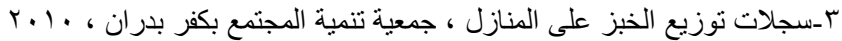

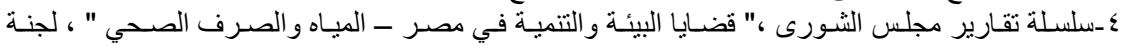

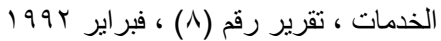

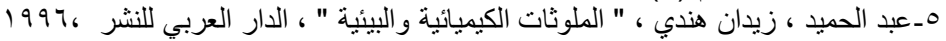

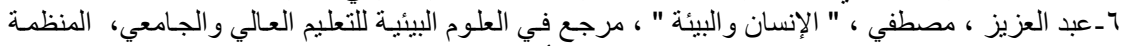

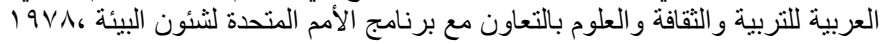

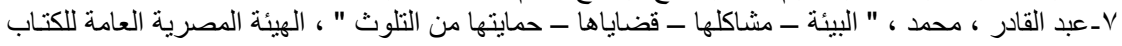

$$
\begin{aligned}
& \text { ، القاهرة ، } 1999 \text { ، }
\end{aligned}
$$

10- Russell ,Train E ," The Role of foundation and universities in Cairo Conservation", California university of california school forestry ,1964.

\section{SOME SOCIAL AND ENVIRONMENTAL VARIABLES EFFECTING RURAL PEOPLE BEHAVIOR REGARDING WATER STREAMS ( VILLAGE FIELD STUDY IN SHARKIA GOVERNORATE ) \\ Mohamed, Zeinab A. and M. H.n Hasan}

Agric. Extension and Rural Development .,Res. Inst.,Agric. Res. center

\section{ABSTRACT}


The main objectives of the Research were : To identify rural knowledge level Regarding polluting water streams their Attitudes toward keeping clean ,polluted practices, and the relationship Between these practices and some social and environmental variables

Study was implemented in one village of sharkia governorate selected purposely A random sample of 150 was chosen, and data were collected from Respondents by questionnaire with personal interview , and data were statistically analyzed By using frequencies, percentages chi - square $(X)^{2}$

Te main results of the study were as follows :

- $47,3 \%$ of the respondent's knowledge regarding water pollution was moclerate, while $38 \%$ of respondent's have positive attitudes towards water conservation and $32 \%$ share in pollution of water streams actually

- Significant relationship at level between degree of water streams pollution and each of the next social variables : educational level ,formal social participation , Ownership farm animals \& polity .

- The most important motivations beside water stream pollution from their point view is missing special places for collecting rubbish, near their houses, and the government ignoring this eases, their suggestions to avoid this problem was to find away to take this rubbish away of their houses

$$
\text { كلية الزراعة - جامعة المنصورة }
$$

\author{
قام بتحكيم البحث إلبث

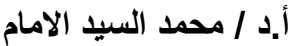 \\ أ.د / أدمد جمال الدين وهيه
}

